\title{
A Sensitive and Specific Genomic RNA Sensor for Point-of-Care Screening of Zika Virus from Serum
}

Cheng Cheng ${ }^{\mathrm{ab}}$, Jie Jayne $\mathrm{Wu}^{\mathrm{b}, *}$, Jiangang Chen ${ }^{\mathrm{c}}$

a School of Engineering and Computer Science, Morehead State University, 150 University Blvd., Morehead, KY, 40351, USA

${ }^{\mathrm{b}}$ Department of Electrical Engineering and Computer Science, The University of Tennessee, 1520 Middle Drive, Knoxville, TN, 37996, USA

${ }^{c}$ Department of Public Health, The University of Tennessee, 1914 Andy Holt Avenue, Knoxville, TN, 37996, USA

\section{Table of contents}

1. Figure S1.

The commercially available surface acoustic wave (SAW) electrode chip utilized for assays at a cost of $\sim \$ 0.80$ USD per test.

2. Table S1.

RNA sequences utilized during probe immobilization on sensor surface for ZIKV gRNA detection

3. Table S2.

Conductivity and phase of different buffer solutions measured at $100 \mathrm{kHz}$ 


\section{Supporting Information}

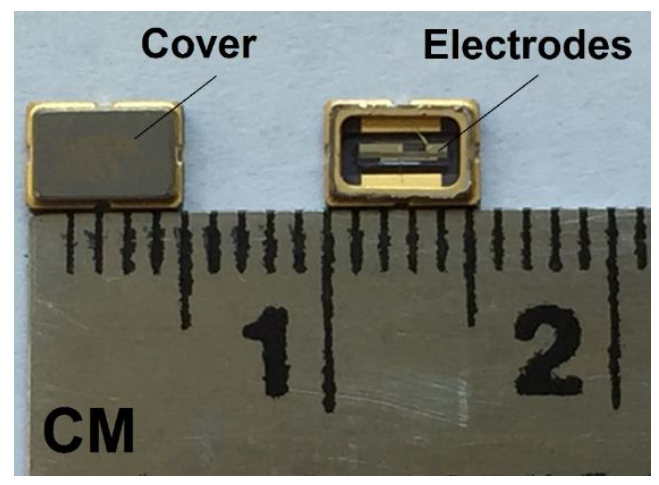

Figure S1. The commercially available surface acoustic wave (SAW) electrode chip utilized for assays at a cost of $\sim \$ 0.80$ USD per test.

Table S1. RNA sequences utilized during probe immobilization on sensor surface for ZIKV gRNA detection

\begin{tabular}{|l|l|l|l|l|}
\hline \multirow{2}{*}{ Probe } & $\begin{array}{l}\text { Target } \\
\text { region }\end{array}$ & $\begin{array}{l}\text { Target } \\
\text { Match }\end{array}$ & $\begin{array}{l}\text { Target } \\
\text { Strain }\end{array}$ & Probe Sequence \\
\hline \multirow{2}{*}{$\# 0$} & $1373-1408$ & $100 \%$ & American & \multirow{2}{*}{ 5'-TTTCGCTCTATTCTCATCAGTTTCATGTCCTGTGTC-3' } \\
\cline { 2 - 4 } & $1433-1462$ & $26 / 36$ & Uganda & \\
\hline$\# 1$ & $3081-3116$ & $100 \%$ & Uganda & 5'-TCTTCAGCCTCCATGTGTCATTCTTTTCACTTTCAA-3' \\
\hline$\# 2$ & $1427-1462$ & $100 \%$ & Uganda & 5'-TTTCGCTCTATCTTCGTCAGTTTCATATCCAATCAT-3' \\
\hline
\end{tabular}

Table S2. Conductivity and phase of different buffer solutions measured at $100 \mathrm{kHz}$

\begin{tabular}{|l|l|l|}
\hline Buffer Solution & Conductivity/(S·m $\left.{ }^{-1}\right)$ & Phase/Deg \\
\hline $0.1 x P B S$ & 0.150 & -4.523 \\
\hline $0.5 x S S C$ & 0.625 & -9.21 \\
\hline 1 xSSC & 1.108 & -13.14 \\
\hline $2 x S S C$ & 2.123 & -19.45 \\
\hline pure serum & 0.861 & -10.33 \\
\hline GuSCN & 10.037 & -38.74 \\
\hline lysing & 0.975 & -14.74 \\
\hline $1: 1(1 \%$ serum)/lysing & 0.443 & -9.759 \\
\hline $1: 1(1 \%$ serum)/GuSCN & 6.256 & -25.43 \\
\hline $1: 1$ serum/lysing & 0.688 & -8.672 \\
\hline $1: 1: 1$ serum:GuSC:2xSSC & 4.259 & -26.19 \\
\hline $2: 1: 1$ serum:GuSC:2xSSC & 3.680 & -23.31 \\
\hline
\end{tabular}

